\title{
MICROPROPAGATION OF MEDICINAL PLANT PLECTRANTHUS BARBATUS
}

\author{
J.D. Barshile \\ Dept. of Botany, Shri Anand College, Patahrdi Dist. Ahmednagar (M.S.) 414102 \\ Corresponding Author: jagannath_barshile@rediffmail.com
}

\begin{abstract}
Communicated : 15.02 .2020
Revision : 17.3.20 \& 19.4.2020

Accepted : 21.05 .2020

Published: 30.05.2020

ABSTRACT:

Plectranthus barbatus is an important medicinal plant. Micropropagation methods for Plectranthus barbatus were established and this method enabled much more efficient propagation of plants. The present work was aimed at evolving a protocol for rapid multiplication of Plectranthus barbatus using micropropagation technique. Explants from node and shoot tip were cultured on MS medium supplemented with different concentrations ( 0.5 to $2.0 \mathrm{mg} / 1)$ of IBA and BAP and their growth responses like shooting and rooting were elucidated. It was observed that shoot tip elicited maximum callusing, shooting and rooting response. Multiple shoots were obtained from explants indicates the micropropagation for commercial scale of production.
\end{abstract}

Keywords: Coleus, Micropropagation, Plectranthus and Tissue culture

\section{INTRODUCTION:}

Plectranthus barbatus syn. Coleus barbatus, is an important medicinal plant with excellent export potential in herbal drug trade. It is also commonly known, as Mainmul. The tubers of this plant are medicinally useful for high blood pressure, spasmolysis, obesity and constipation. A diterpene compound, forskolin obtained from tuberous root of this plant has been used for glaucoma congestive, asthma and certain cancers (Praveena et al, 2012). The forskolin has a unique property of activating almost all hormone sensitive adenylatecyclase enzymes in a biological system (Bhatet al., 1977). Forskolin is reported to be useful in the treatment of congestive heart failure, glaucoma, asthma and certain type of cancers (Tandon et al., 1977).

It is an important plant used against various disorders in indigenous systems of medicine such as anti-aging, antioxidant, as a remedy for heart, abdominal and respiratory disorders by Seamon and Daly (1981). In addition, it has been shown to have anti-inflammatory property in forskolin (Zhang et al., 1977).
In spite of its high medicinal value, the yield of forskolin in Plectranthus is very low. Forskolin is usually produced by extraction from roots of the plant. Commercial cultivation of Plectranthus required large number of seedlings. Attempts have been made to provide additional sources to provide the pharmaceutical demand for forskolin through plant biotechnology technique in past. Few references that deal with micropropagation of Plectranthus species can be found in literature (Rajasekharan et al., 2005 and Shrinivasan et al., 2006). Micropropagation is one of the potential techniques aimed at rapid production of seedling. The present work is under taken to assess the suitability and find out the effective concentration of plant growth hormones for micropropagationin Plectranthus barbatus.

\section{MATERIALS AND METHODS:}

Experimental plant material, used in the present investigation, was Plectranthus barbatus syn. Coleus barbatus) commonly known as Mainmul. It belongs to the family Labiate 
(Lamiaceae). Plants of Mainmul were procured from Dhanwantari Udyan (Medicinal Garden) of Mahatma Phule Krishi Vidyapeeth, Rahuri (M.S.) and established in the botanical garden.

Establishment of plant tissue culture: This research was carried out in the Plant Tissue Culture Laboratory of Shri Anand college Patahrdi. Explants were washed with water for $30 \mathrm{~min}$. and treatment with $1 \%$ antifungal for 5 min, samples were washed three times with sterile distilled water. Nodal segment of explant was surface sterilized using $70 \%$ ethanol and $10 \%$ sodium hypochlorite for $5 \mathrm{~min}$. Explant were washed three times with sterile distilled water and cultured on MS medium (Murashige and skoog, 1962) supplemented with different concentrations of auxin (IBA) and cytokinin (BAP). The basic nutrient medium (MS) contained mineral salts, vitamins, $3 \%$ sucrose, and $0.7 \%$ agar. The $\mathrm{pH}$ was adjusted to 5.8. The media were sterilized by autoclaving. 50 explants were cultured for each treatment. Cultures were incubated in the light for $10 \mathrm{~h}$ (light 3000 lux, temperature $25 \pm 1{ }^{\circ} \mathrm{C}$, humidity $60-70 \%)$. The nodal segments derived shoots were transferred to MS medium supplemented with different concentrations of cytokinin. The number of shoots were determined after 30 days of culture; the experiments were repeated three times.

\section{RESULTS AND DISCUSSION:}

Table 1 shows the results obtained with the nodal segments of Plectranthus barbatus in micropropagation. Significant differences in the shoots multiplication rate were detected between the treatments containing $1.5 \mathrm{mg} / 1$ and $2.0 \mathrm{mg} / 1$ BAP $\quad(14.85$ and 11.37 shoots/explant, respectively) and the other treatments. The treatment containing $1.5 \mathrm{mg} / 1 \mathrm{BAP}$ showed callus production. Although callus production was important in the treatment with $1.5 \mathrm{mg} / 1 \mathrm{BAP}$, no vitrification was detected in this treatment. All recovered shoots rooted spontaneously. No problem was detected for the acclimatization step, all plants transferred to pots were successful. These results indicate that for an efficient in vitro micropropagation of Plectranthus barbatus in order to avoid undesirable responses, the levels of BAP must be carefully adjusted.

Rooting on multiple shoots was made easy when sub cultured on rooting medium containing different concentrations of IBA. The IBA $1.0 \mathrm{mg} / 1$ was ideal for roots and shoots formed from medium with BAP were separated and rooted on rooting medium. Since, many plantlets are formed from multiple shoots, for mass propagation in shorter period multiple shoots are preferred. The lower concentrations have stimulated in a greater measure formation of roots than in the case of using higher concentrations. Increasing the IBA concentrations lowered the quality and number of roots reported earlier in Aloe veraby Ahmed, et al., (2007) and MS medium containing $1 \mathrm{mg} / 1$ IBA was more effective for rooting than medium with other concentrations have been reported by Baksha et al., and Gholamreza (2013). In fact, to start with the rapid multiplication of any commercially important medicinal plant, the fine-tuning of in vitro micropropagation is required as the first step. The tissue culture experiment in this study showed that Plectranthus barbatus presented a strict hormonal and nutritional requirement.

\section{CONCLUSION:}

$1.5(\mathrm{mg} / \mathrm{l})$ concentration BAP and $1 \quad(\mathrm{mg} / \mathrm{l})$ concentration of IBA was found to be effective for the micropropagation of Plectranthus. Therefore $1.5(\mathrm{mg} / \mathrm{l})$ BAP and $1(\mathrm{mg} / \mathrm{l})$ IBA concentrations could be more effective for micropropagation of Plectranthus.

\section{ACKNOWLEDGE:}

I am thankful to the UGC (WRO) for providing financial assistance (File No. 47-41/08) and 
Principal Shri Anand College, Pathardi for providing necessary laboratories facilities to carry out present work.

\section{REFERENCES:}

Ahmed, S., A.H. Kabir, M.B. Ahmed, M.A. Razvy and S. Ganesan, 2007. Development of Rapid micropropagation methood of Aloe vera $\mathrm{L}$. Seed Sci. Journal. 24:121-128.

Baksha, R., M.A.A. Jahan, R. Khatum and J. L. Munshi, 2005.Micropropagation of Aloe barbadensis Mill. through In vitro Culture of Shoot tip Explants. Plant tissue Cult. and Biotech. 15(2):121-126.

Bhat, S.V., B. S. Bajwa, H. Dornauer, N.J. de Souza and H.W. Fehlhaber, 1977.Structure and stereochemistry of a new lab danediterpenoid from Coleus forskohlii Briq. Tetrahedron Letters. 19:1669-1672.

Gholamreza, A., H. Mohammad and M. Mohammad, 2013.InvitroMicropropagation of Aloe vera- Impacts of Plant Growth Regulators, Media and Types of Explants. J. Biol. Environ. Sci. 7(19): 19-24.

Murashige, T. and F. Skoog, 1962.A revised medium for rapid growth and bioassays with tobacco tissue cultures. Physiol. plantarum. 15: 473-497.
Praveena, R., S. A. Pandian, and M. Jegadeesan, 2012.In vitro culture studies on medicinal herb-Coleus forskohlii Briq. Libyan Agri. Research Center J. International. 3: 3032.

Rajasekharan, P.E., S.R. Ambika and S. Ganeshan, 2005.In Vitro conservation of Coleus froskohlii an endangered medicinal plant. J. of plant Biotechnology.7(2):1-7.

Seamon, K.B. andJ.W. Daly, 1981.Forskolin: a unique diterpene activator of cyclic AMPgenerating systems. J. of cyclic Nucleotide Res. 7(4):201-224.

Shrinivasan, M. V. Nachiappan and K. Rajasekharan, 2006. Potential application of Urea-derived herbicides as cytokinins in plant tissue culture.J. of Bio. Sci. 31(5):599-605

Tandon, J. S., M.M. Dhar, S. Ramakumar and K. Venkatesan, 1977. Structure of a Biologically active diterpene from Coleus forskohlii. Indian J. Chem. 15B: 880 883.

Zhang, G., Y. Liu, A.E. Ruoho and J.H. Hurley, 1997. Structure of the adenylyl cyclase catalytic core. Nature. 20;386(6622):247253. 

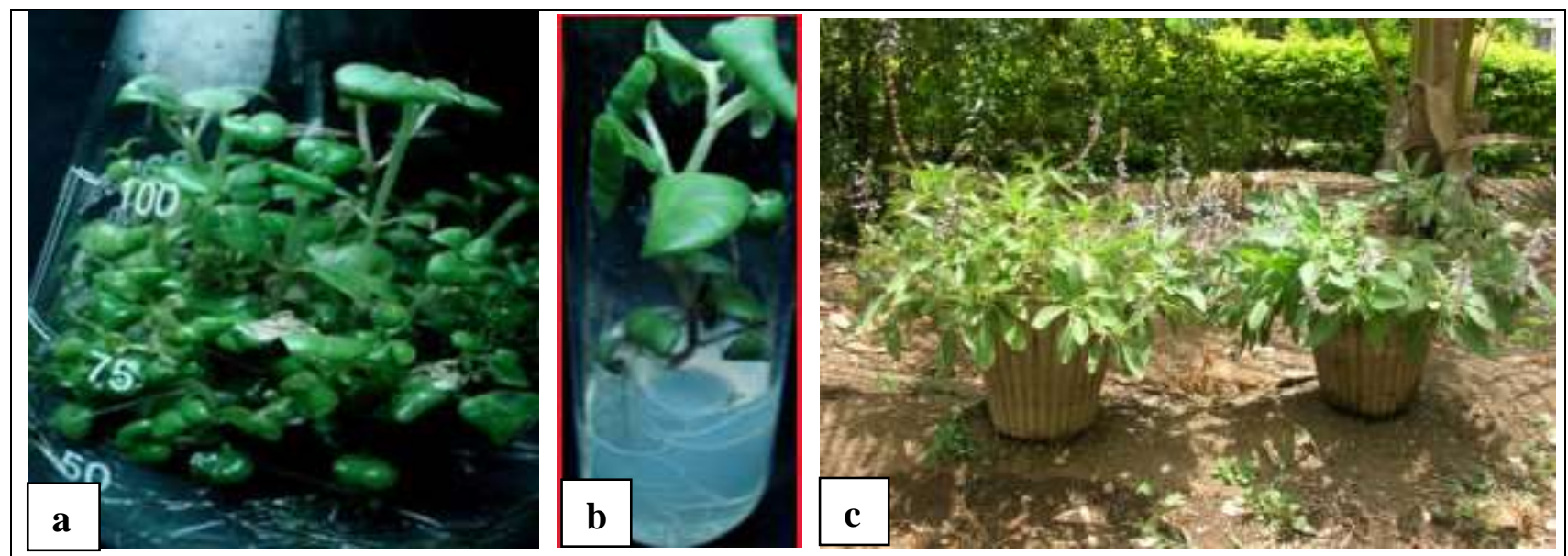

Figure1. Micropropagation of Plectranthus barbatus a. multiple shoot, b. induction of rooting and c. hardening.

Table 1. Response of Plectranthus barbatus toward different concentrations of BAP and IBA

\begin{tabular}{|c|c|c|c|c|}
\hline \multirow{2}{*}{\begin{tabular}{c} 
Treatment \\
\cline { 2 - 5 }
\end{tabular}} & 0.5 & 1 & 1.5 & 2 \\
\hline $\begin{array}{c}\text { Number of shoots per } \\
\text { plant }\end{array}$ & $5.22 \pm 0.37(\mathrm{~S})$ & $6.41 \pm 85(\mathrm{~S})$ & $14.85 \pm 1.03(\mathrm{~S})(\mathrm{C})$ & $11.37 \pm 0.86(\mathrm{~S})$ \\
\hline \begin{tabular}{c} 
Treatment \\
\cline { 2 - 5 }
\end{tabular} & 0.5 & 1 & 1.5 & 2 \\
\hline $\begin{array}{c}\text { Number of root per } \\
\text { plant }\end{array}$ & $4.8 \pm 0.4$ & $7.49 \pm 0.24$ & $6.4 \pm 0.37$ & $3.7 \pm 0.32$ \\
\hline
\end{tabular}

Letters in brackets indicates the main response for each treatment. (s): shoot (c): callus. Average and SD of the shoots and root number per explant of three replications $n=10$. 